\title{
Loss of immiscible nitrogen from metallic melt explains Earth's missing nitrogen
}

\author{
J. Liu ${ }^{1 *}$, S.M. Dorfman ${ }^{1 *}$, M. Lv¹, J. Li², F. Zhu², Y. Kono ${ }^{3,4}$
}

Abstract

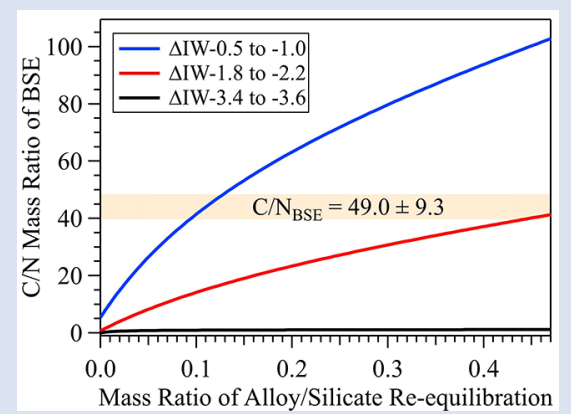

Nitrogen and carbon are essential elements for life, and their relative abundances in planetary bodies are important for understanding planetary evolution and habitability. The high $\mathrm{C} / \mathrm{N}$ ratio in the bulk silicate Earth (BSE) relative to chondrites has been difficult to explain through partitioning during core formation and outgassing from molten silicate. Here we propose a new model that may have released nitrogen from the metallic cores of accreting bodies during impacts with the early Earth. Experimental observations of melting in the Fe-N-C system via synchrotron $\mathrm{X}$-ray radiography of samples in a Paris-Edinburgh press reveal that above the liquidus, iron-rich melt and nitrogen-rich liquid coexist at pressures up to at least $6 \mathrm{GPa}$. The combined effects of N-rich supercritical fluid lost to Earth's atmosphere and/or space as well as N-depleted alloy equilibrating with the magma ocean on its way to the core would increase the BSE C/N ratio to match current estimates.

Received 2 January 2019 | Accepted 8 June 2019 | Published 30 July 2019

\section{Introduction}

The habitability of Earth and other planetary bodies depends on the incorporation, distribution, and speciation of volatile elements including carbon and nitrogen. In Earth, the BSE $\mathrm{C} / \mathrm{N}$ ratio is estimated to be higher than that of planetary building blocks including enstatite, carbonaceous chondrites, interstellar dust and gas (e.g., Marty, 2012; Bergin et al., 2015). Recent studies estimate the BSE C/N ratio to be superchondritic based on measurements of gas bubbles trapped in mid-ocean ridge and ocean island basalts (Marty, 2012; Halliday, 2013; Bergin et al., 2015), and recent estimates of the BSE C/N ratio converge to $49 \pm 9$ (Bergin et al., 2015). In contrast, $\mathrm{C} / \mathrm{N}$ ratios measured in primitive $\mathrm{CI}$ chondrites (17 \pm 3 ; Alexander et al., 2013) and enstatite chondrites (14 \pm 12 ; Grady and Wright, 2003) are significantly lower. Explaining these observations thus requires one or more mechanisms that preferentially deplete $\mathrm{N}$ relative to $\mathrm{C}$ from the mantle source of basalt magmas.

The key processes responsible for $\mathrm{C}$ and $\mathrm{N}$ redistribution among Earth reservoirs were equilibrium partitioning between the magma ocean and the growing metallic core and degassing of the magma ocean to the early atmosphere, but these processes have been insufficient to explain the estimated high BSE C/N ratio (Bergin et al., 2015; Hirschmann, 2016; Dalou et al., 2017). Core formation is expected to decrease the $\mathrm{BSE} \mathrm{C} / \mathrm{N}$ ratio because at relevant conditions $\mathrm{C}$ is a much stronger siderophile element than N (e.g., Dalou et al., 2017). Degassing has not been thought to significantly affect the $\mathrm{C} / \mathrm{N}$ ratio, as chemical analysis of volatiles in silicate glasses quenched from high pressure-temperature $(P-T)$ experiments indicates that the solubilities of $\mathrm{C}$ and $\mathrm{N}$ in the magma ocean are comparable (Hirschmann, 2016).

The major host phase for both $\mathrm{C}$ and $\mathrm{N}$ in the solidifying planet is likely to be core-forming alloy, therefore understanding the Fe-N-C system under relevant conditions may hold the key to the paradox of the high BSE C/N ratio. While the $\mathrm{Fe}-\mathrm{C}$ phase diagram has been well studied over a wide range of pressures (e.g., Fei and Brosh, 2014; Liu et al., 2016), very limited data are available on the phase relations of the Fe-N system (e.g., Guillermet and Du, 1994). In particular, melting behaviours are expected to be different in these two systems, as the C-rich end member, graphite/diamond, has a melting point of 4000-5000 K at relevant pressures (Grumbach and Martin, 1996), while the N-rich end member would be gas/ supercritical fluid in the BSE.

\section{Immiscible N-rich Fluid}

In order to test whether the mobility of N-rich gas/fluid could provide a possible mechanism to leak $\mathrm{N}$ during accretion and core formation, we investigated melting relations in the Fe-N-C system under high pressures by in situ $\mathrm{X}$-ray radiography and

\footnotetext{
1. Department of Earth and Environmental Sciences, Michigan State University, MI 48824, USA

2. Department of Earth and Environmental Sciences, University of Michigan, MI 48109, USA

3. HPCAT, Geophysical Laboratory, Carnegie Institution of Washington, IL 60439, USA

4. Geodynamics Research Center, Ehime University, Ehime 790-8577, Japan

Corresponding author (email: jiacliu09@gmail.com, dorfman3@msu.edu)
} 


\section{Before melting}

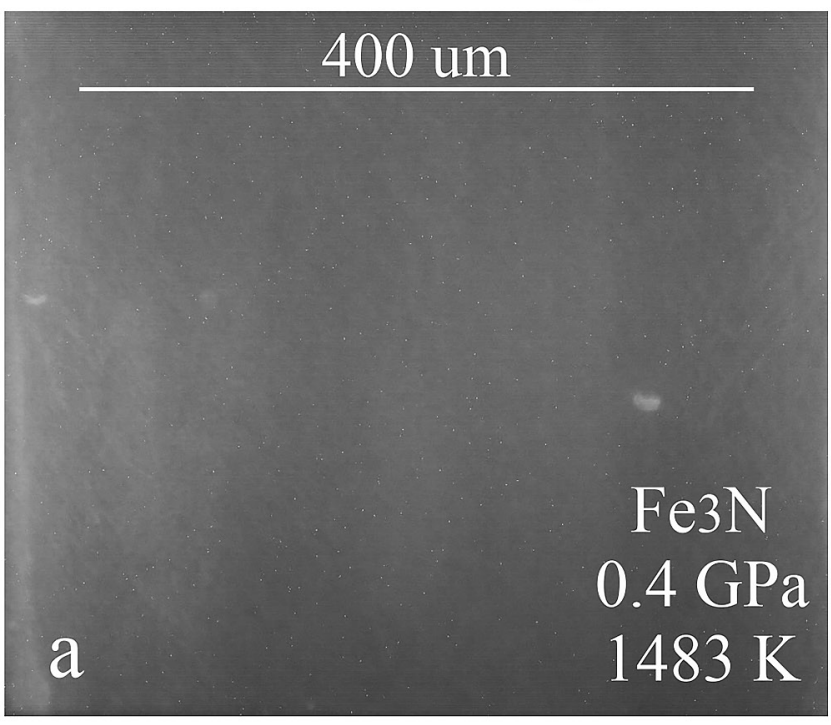

\section{N-rich liquid dissolves}

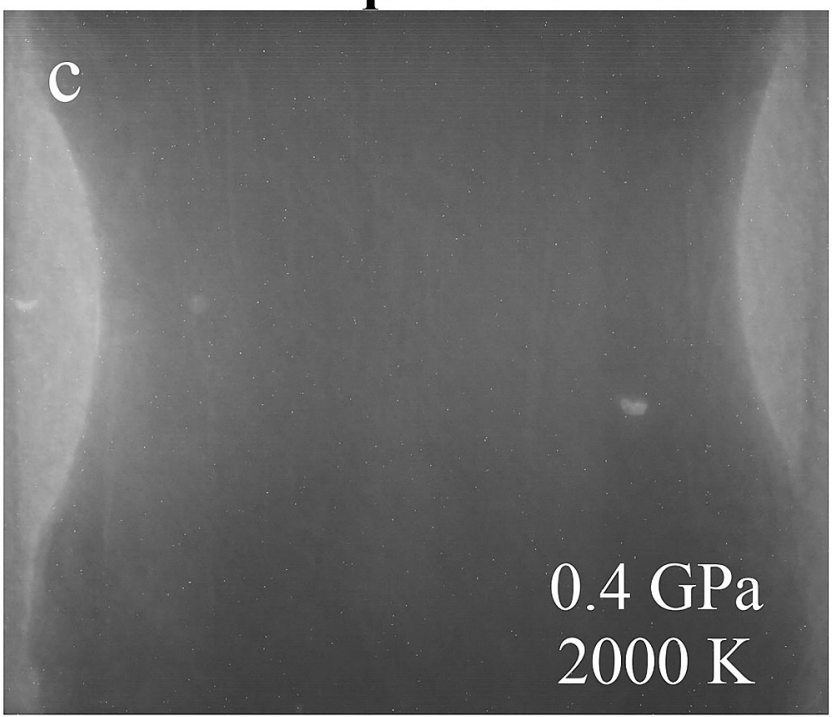

Two immiscible liquids

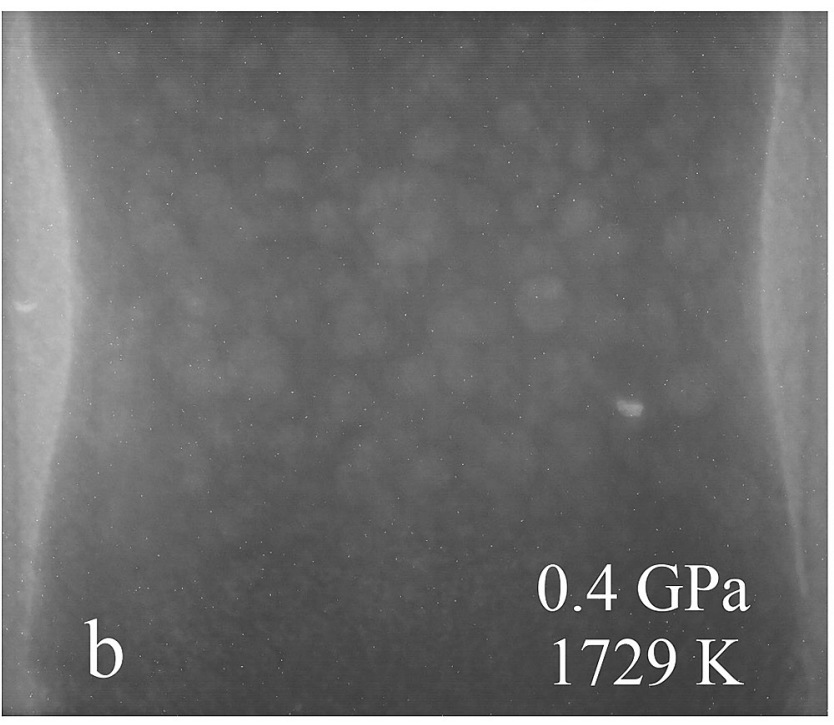

N-rich liquid re-exsolves

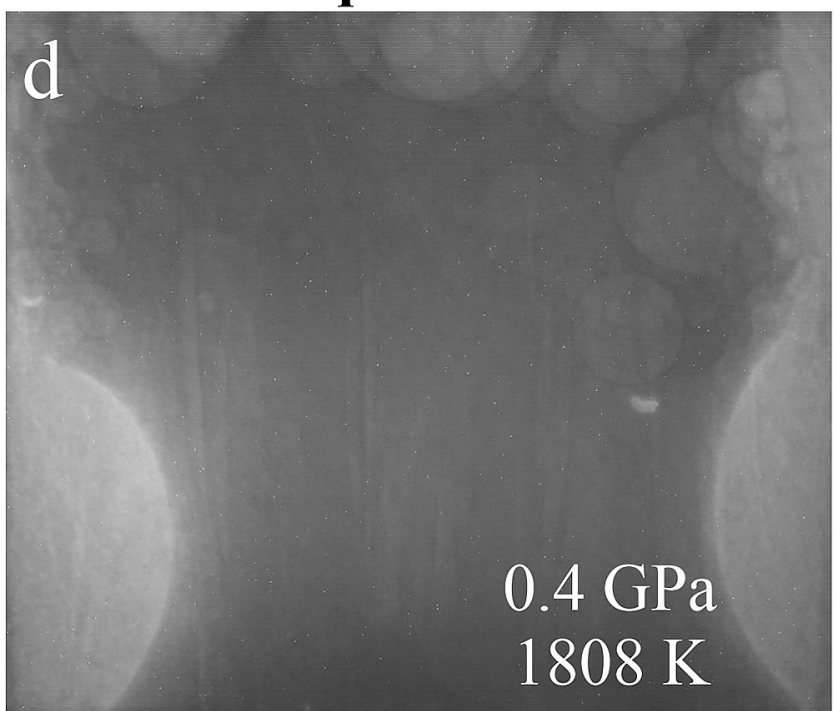

Figure 1 Representative X-ray radiographic images showing the evolution of the miscibility gap in Fe-N-C system under high pressure and high temperature conditions (run 4-17). This in situ X-ray radiography experiment starts at $0.4 \mathrm{GPa}$ with Fe $\mathrm{N}$ as the starting material. (a) The sample is below solidus at $0.4 \mathrm{GPa}$ and $1483 \mathrm{~K}$. (b) Around $1729 \mathrm{~K}$, immiscible N-rich supercritical fluid coexists with metallic liquid. (c) At higher temperatures, N-rich supercritical fluid partially dissolves into metallic liquid. (d) Lowering temperature re-exsolves $\mathrm{N}$-rich supercritical fluid from metallic liquid. The corresponding movie is shown in Video S-1.

X-ray diffraction (XRD) coupled with Paris-Edinburgh (PE) cells and ex situ chemical analysis. The starting materials are either iron nitrides $\left(\mathrm{Fe}_{3} \mathrm{~N}\right.$ and $\left.\mathrm{Fe}_{4} \mathrm{~N}\right)$ or a mixture of iron and iron nitride powders with or without graphite powders. The starting $\mathrm{N}$ and $\mathrm{C}$ contents range from $0-7.7 \mathrm{wt}$. \% and $0-10.0$ wt. \%, respectively (Table S-1). A standard PE sample assembly configuration was employed (Kono et al., 2014), which used X-ray transparent $\mathrm{MgO}$ as the sample capsule and a cylindrical graphite tube outside sample capsule as the heater. Assemblages were first compressed to target pressures and gradually heated to be fully molten. Then the molten samples were quenched below $500 \mathrm{~K}$ within 5 seconds to preserve compositions for ex situ chemical analysis (Table S-1).

Below the solidus, starting materials for all runs were homogenous at $\sim 3 \mathrm{~mm}$ spatial resolution of $X$-ray radiographic images (e.g., Fig. 1a). An upper bound for the onset of partial melting at higher temperature was indicated by the appearance of 10s-micron regions of low X-ray absorption (e.g., Fig. S-1b).
At higher temperatures, these lighter regions merged to form 10 s to 100 s-micron droplets which moved vigorously (Fig. 1b). XRD patterns during heating also recorded the melting process (Fig. S-1d): at $0.4 \mathrm{GPa}$ and $300 \mathrm{~K}$, the XRD pattern confirmed $\mathrm{Fe}_{3} \mathrm{~N}$ as the starting material; at $\sim 1690 \mathrm{~K}$, most crystalline peaks disappeared an obvious increase in background at $\sim 34-80 \mathrm{keV}$ (Fig. S-1d), which originated from diffuse scattering signal. The corresponding $\mathrm{X}$-ray radiographic image (Fig. S1-b) showed the ubiquitous occurrence of the low X-ray absorption regions. Therefore, both the XRD pattern and X-ray radiographic image indicated a partially molten state of the Fe-N sample. Turbulent flow of two phases occurred above $\sim 1725 \mathrm{~K}$ (Video S-1), and the corresponding XRD pattern exhibited diffuse scattering with no XRD peaks (Fig. S-1d) and thus indicated conditions above the liquidus but below the solvus. At higher temperatures, the immiscible droplets partially dissolved into the metallic liquid but persisted to the highest temperature investigated in run 4-17 ( 2000 K, Fig. 1c). Lowering temperature made more immiscible droplets 


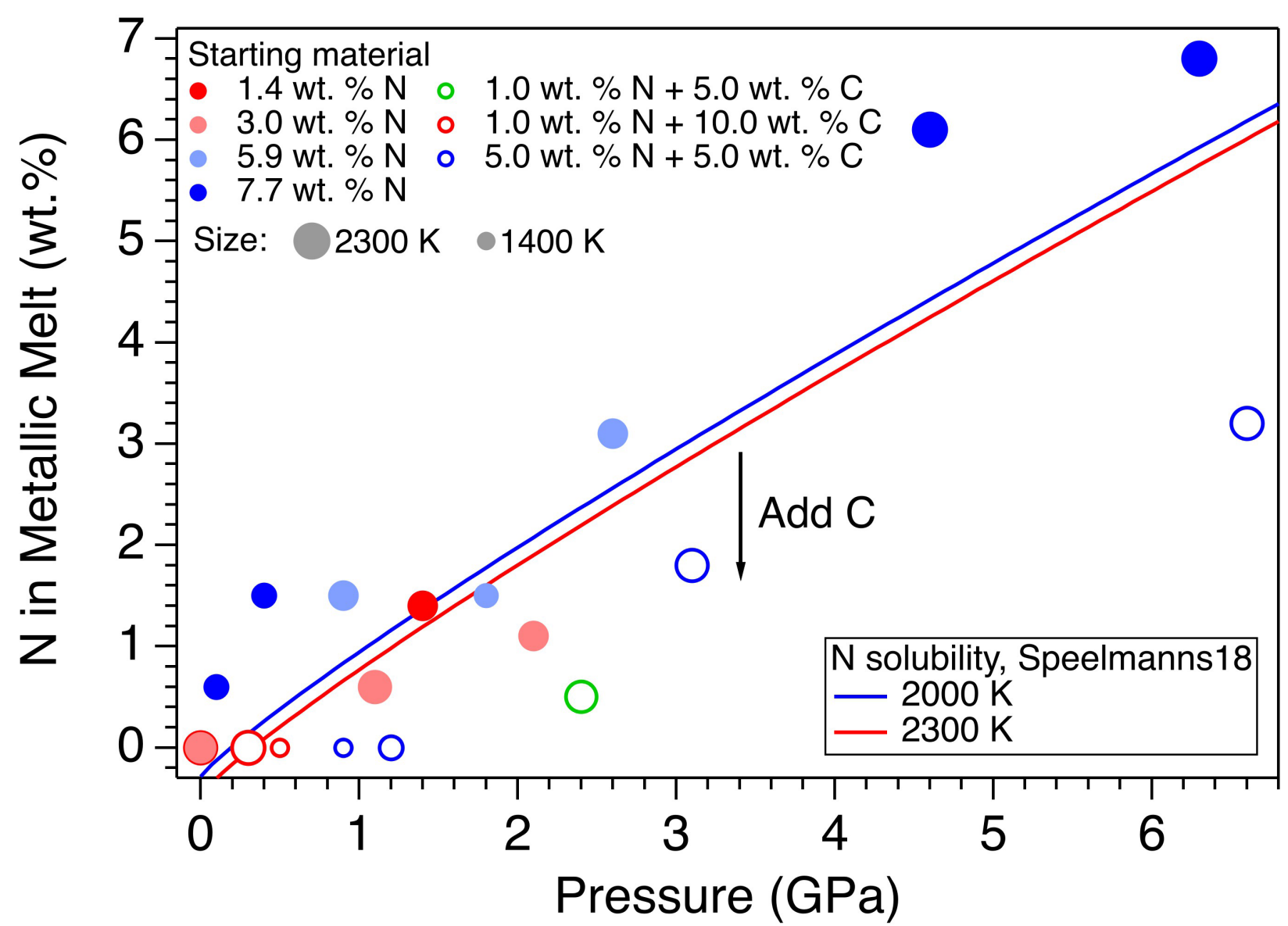

Figure 2 The pressure dependence of $\mathrm{N}$ solubility in Fe-N-C melt. The solid circles are for Fe- $\mathrm{N}$ starting materials; the open circles are for Fe-N-C starting materials. Symbol sizes are proportional to the temperatures $(1400-2300 \mathrm{~K})$ at which the experiments are quenched and colours indicate initial compositions (see legend). The blue and red curves are modelled $\mathrm{N}$ solubilities in Fe- $\mathrm{N}-\mathrm{C}$ melt at $2000 \mathrm{~K}$ and $2300 \mathrm{~K}$, respectively, from Speelmanns et al. (2018).

re-exsolve (Fig. 1d), confirming that the disappearance of the immiscible droplets from Figures $1 \mathrm{~b}$ to $1 \mathrm{c}$ cannot be explained by loss of $\mathrm{N}$-rich fluid through the $\mathrm{MgO}$ capsule. In comparison, no inhomogeneity appeared at all in Fe melting experiments at $0.8 \mathrm{GPa}$ up to $2103 \mathrm{~K}$ (Fig. S-2).

The immiscible droplets with lighter colours in X-ray radiographic images are enriched in $\mathrm{N}$ because the contrast in $X$-ray radiographic images reflects density differences (Kono et al., 2015). The N-rich nature of the immiscible fluid is confirmed by ex situ chemical analysis of the quenched samples: for experiments quenched with the presence of immiscible liquids, the regions which are lighter in $\mathrm{X}$-ray radiographic images correspond to voids in recovered samples (e.g., Figs. S-3 to $\mathrm{S}-6) ; \mathrm{N}$ contents in the recovered samples are lower than the starting values when immiscible melting occurs (Table S-1). For example, $\mathrm{N}$ content in run $4-16$ decreases from $5.9 \%$ in the starting materials to $1.5 \%$ in the recovered sample (Fig. $\mathrm{S}-3)$. With increasing temperature, the increase of $\mathrm{N}$ solubility in metallic melt (e.g., Fig. 1 and Video S-1) can be explained by the concave-down shape of the solvus, which marks the phase boundary between one liquid and two immiscible liquids (Fig. S-7). A similar phenomenon has been observed in the Fe-O system (Kowalski and Spencer, 1995; Tsuno et al., 2007): at 1 bar, $\mathrm{O}$ solubility increases from $\sim 0$ to $\sim 5 \mathrm{~mol}$. \% when temperature increases from $\sim 1811 \mathrm{~K}$ to $\sim 2340 \mathrm{~K}$ (Kowalski and Spencer, 1995). Such a miscibility gap persists to at least $21 \mathrm{GPa}$ in the $\mathrm{Fe}-\mathrm{O}$ system and $\mathrm{O}$ solubility in metallic melt increases with a rate of 0.01-0.03 mol./K between 15-21 GPa and 2050-2350 K (Tsuno et al., 2007). For experiments with C added to the starting materials, immiscible melting also occurs (Figs. S-5 and S-6). C contents in the recovered samples are the same as starting materials within uncertainty (Table S-1). This indicates that $\mathrm{C}$ does not dissolve into N-rich fluid during immiscible melting.

The combination of in situ and ex situ analysis was employed to constrain the solubility of $\mathrm{N}$ in Fe-N-C alloys (Fig. 2). Near 1 bar in all compositions up to 7.7 wt. \% N and $10.0 \mathrm{wt}$ \% C, immiscibility of N-rich supercritical fluid and metallic melt observed in situ persists to at least $2273 \mathrm{~K}$, the highest temperature investigated here. Solubility of $\mathrm{N}$ in $\mathrm{Fe}-\mathrm{N}-\mathrm{C}$ alloy increases from almost 0 near 1 bar to $~ 6.8 \mathrm{wt}$. \% $\mathrm{N}$ at $6.3 \mathrm{GPa}$, as the highest pressure investigated here (Fig. 2). The pressure required for closing the miscibility gap increases with the starting $\mathrm{N}$ and $\mathrm{C}$ contents (Fig. 2). For Fe-1.4 wt. \% $\mathrm{N}$ starting material at about 0-0.1 GPa, immiscible liquids persist to at least $1980 \mathrm{~K}$, but no immiscible liquids appear at $\sim 1.4 \mathrm{GPa}$ up to $2000 \mathrm{~K}$ (Fig. S-6). In contrast, for Fe-7.7 wt. \% $\mathrm{N}$ starting composition the solvus persists to at least $6.3 \mathrm{GPa}$ (Fig. 2). Adding 5-10 wt. \% C in the starting materials expands the pressure range of the solvus by about 2-5 GPa (Fig. 2). This is because $\mathrm{C}$ is more siderophilic than $\mathrm{N}$ and it expels $\mathrm{N}$ from metallic melt to the immiscible fluid.

A recent study also infers the presence of $\mathrm{N}$-rich fluid from $\mathrm{Fe}-\mathrm{N}-\mathrm{C}$ melt based on the ex situ analysis of quenched samples (Speelmanns et al., 2018). The trend of their N solubility model is consistent with our data (Fig. 2). However, the $\mathrm{C}$ and $\mathrm{Pt}$ contaminations up to $12.5 \mathrm{wt}$. \% from sample capsules are not incorporated into their $\mathrm{N}$ solubility models (Speelmanns et al., 2018), which may explain the offsets between these two studies (Fig. 2). The presence of immiscible N-rich fluid in silicate-alloy systems has been observed 


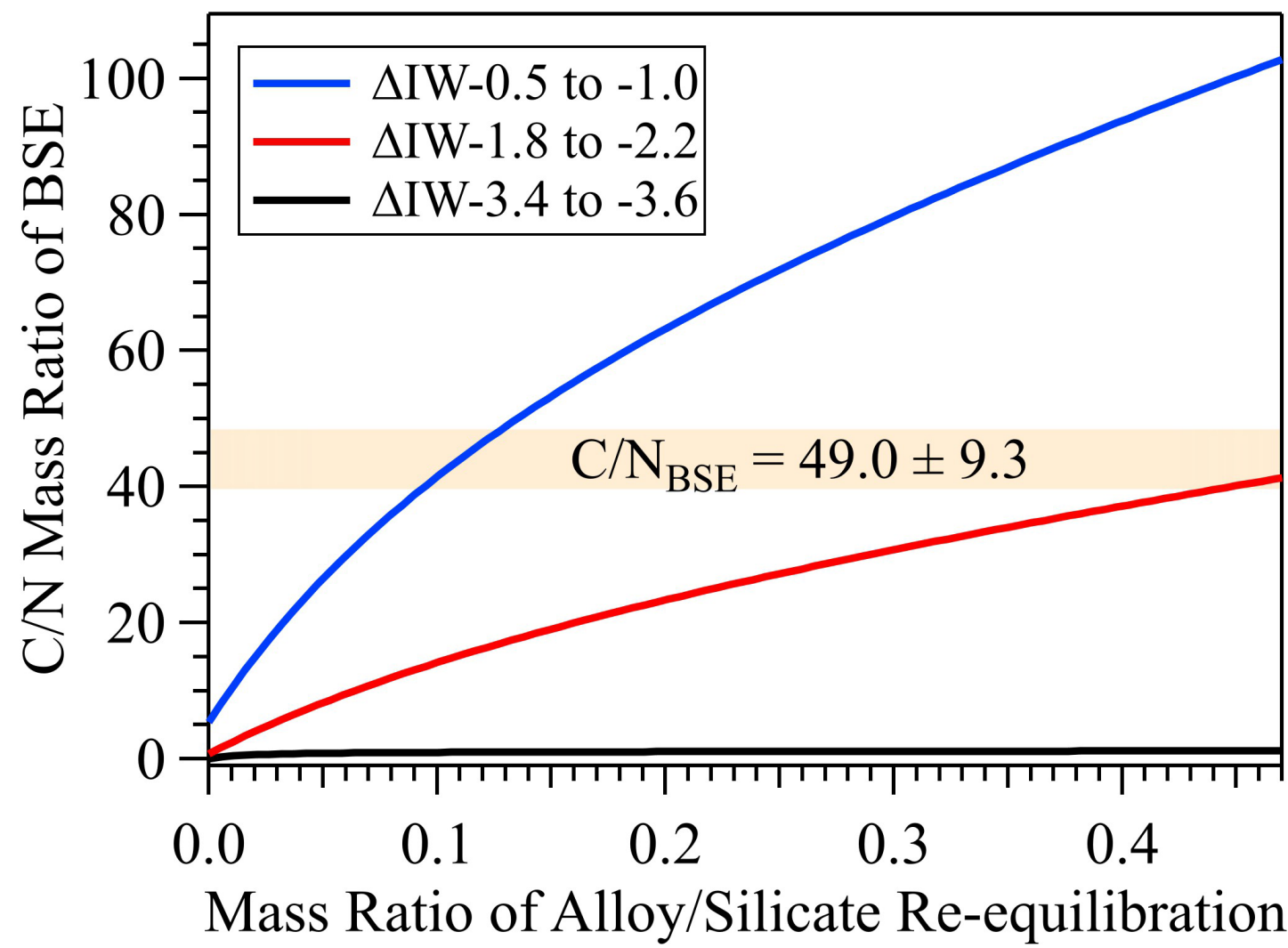

Figure 3 The evolution of the BSE C/N ratio with the degree of re-equilibration between alloy and silicate melts during core formation. The blue curve is calculated at oxidised conditions ( $\Delta \mathrm{IW}-0.5$ to $\Delta \mathrm{IW}-1.0)$; the red curve is for reduced conditions ( $\Delta \mathrm{IW}-1.8$ to $\Delta \mathrm{IW}-2.2$ ) and the black curve is for very reduced conditions ( $\Delta \mathrm{IW}-3.4$ to $\Delta \mathrm{IW}-3.6$ ). The horizontal yellow bar marks the range of the estimated present BSE C/N ratio (Bergin et al., 2015).

in a previous partitioning study on metallic-silicate melts up to 10 GPa (Roskosz et al., 2013), supporting that this immiscible phenomenon could occur in a realistic magma ocean phase assemblage.

\section{Missing $\mathbf{N}$ in the Mantle}

The conundrum of missing $\mathrm{N}$ in the mantle can be solved by accounting for immiscibility of $\mathrm{N}$ in the $\mathrm{Fe}-\mathrm{N}-\mathrm{C}$ system in modelling Earth's $\mathrm{N}$ budget. Our model calculates the BSE $\mathrm{C} / \mathrm{N}$ ratio in three steps (Fig. S-8 and SI): first, we assume Earth-forming impactors have alloy core and silicate mantle in equilibrium with average alloy/silicate mass ratio of 0.46 , same as the Earth's core/mantle mass ratio. The amount of $\mathrm{N}$ stored in metallic core is controlled by oxygen fugacity (Dalou et al., 2017): $90.2 \% \mathrm{~N}$ would stay in the core at oxidised bodies ( $\Delta \mathrm{IW}-0.5$ to -1.0 ); this number decreases to $69.7 \%$ and $12.1 \%$ at modestly reduced ( $\Delta \mathrm{IW}-1.8$ to -2.2$)$ and more reduced bodies ( $\Delta \mathrm{IW}-3.4$ to -3.6$)$, respectively (Fig. S-9). In contrast, previous models assume all $\mathrm{C}$ and $\mathrm{N}$ are initially stored in silicate (Bergin et al., 2015; Hirschmann, 2016; Dalou et al., 2017). This assumption sets the initial BSE C/N ratio at 25 without loss of the primordial atmosphere, which is about 20-24 higher than our initial BSE C/N ratios (Fig. 3). Secondly, we assume that extensive melting of alloy during high energy impacts induces immiscible melting, resulting in loss of all $\mathrm{N}$ stored in impactors' cores to space. In general, the fraction of $\mathrm{N}$ released from an impactor depends on the core/mantle mass ratios in the accreting bodies: the degree of melting during accretion/melting, the extent of immiscibility between N-rich supercritical fluid and metallic melt, and the fraction of atmospheric $\mathrm{N}$ loss to space. As our model assumes impactor cores melt completely and release $\mathrm{N}$ at the magma ocean surface, it yields an upper limit for $\mathrm{N}$ loss at this stage. The loss of $\mathrm{N}$ results in an extremely high $\mathrm{C} / \mathrm{N}$ ratio in the metallic phase. Once such $\mathrm{N}$-depleted metallic droplets sink below the depth where solubility of $\mathrm{N}$ in alloy increases (Fig. S-8), N could partition from the magma ocean into $\mathrm{N}$-depleted alloy droplets and therefore elevate the BSE C/N ratio as the alloy joins Earth's growing core.

Overall, the loss of $\mathrm{N}$ from impactor cores could significantly lower Earth's bulk $\mathrm{N}$ budget and therefore raise the BSE C/N ratio (Fig. 3). Because $\mathrm{N}$ partitions more strongly into alloy under more oxidised conditions, more $\mathrm{N}$ is subject to loss from oxidised accreting bodies (Fig. S-9). Similarly, the subsequent core formation would also result in a higher $\mathrm{C} / \mathrm{N}$ ratio of the BSE under oxidised conditions (Fig. 3). Over time during core formation, $f_{\mathrm{O}_{2}}$ is estimated to evolve from lower values of $\Delta \mathrm{IW}-3.9$ to $\Delta \mathrm{IW}-1.9$ to higher values of $\Delta \mathrm{IW}-1.9$ to $\Delta$ IW-1.0 (Rubie et al., 2011, Badro et al., 2015). Therefore, the BSE C/N ratio is expected to evolve from 0.03-0.5 at very reduced conditions to $0.7-41.4$ at reduced conditions and finally to 5-130.0 at slightly reduced conditions (Fig. 3). Compared with previous models (Bergin et al., 2015), our model matches the estimated BSE C/N ratio for an extensive range of redox conditions, the degree of alloy-silicate re-equilibration and extent of loss of nascent atmosphere during accretion and core formation. Notably, both $\mathrm{C}$ and $\mathrm{N}$ form accessory minerals, such as diamonds, iron carbides and iron/titanium/chromium nitrides (e.g., Fegley, 1983; Javoy, 1997; Kaminsky and Wirth, 2017), which have not been considered in the estimated BSE $\mathrm{C} / \mathrm{N}$ ratio yet. In addition, the presence of deep mantle carbonates (e.g., Brenker et al., 2007) and high solubilities (10s to 1000s $\mathrm{mg} / \mathrm{g}$ ) of $\mathrm{N}$ in transition zone and lower mantle minerals (Yoshioka et al., 2018), both of which are sensitive to redox and $\mathrm{pH}$ conditions (e.g., Rohrbach and Schmidt, 2011; Mikhail et al., 2017), would also influence the estimation of the BSE $\mathrm{C} / \mathrm{N}$ ratio. 
Vapourisation during accretion has recently been evoked to explain $\mathrm{Mg}$, Si and Fe isotopic compositions in the BSE (Hin et al., 2017) and the pattern of volatile element depletion (Norris and Wood, 2017), indicating its critical role in the early stage of Earth evolution. Considering the high $\mathrm{C} / \mathrm{N}$ ratios $(>10)$ of most planetary bodies (Bergin et al., 2015), the $\mathrm{C} / \mathrm{N}$ ratios of the impactors' cores would be even higher and therefore promote immiscible melting during impact. In addition, for Earth-like planets at the proposed synestia stage (Lock and Stewart, 2017), the magma ocean is surrounded by massive vapourised materials, which are at pressures between 0.1 bar and 1.0 GPa. In this stage, the loss of $\mathrm{N}$ through immiscible fluid could significantly shape the BSE C/N ratio.

\section{Acknowledgements}

S.M. Dorfman acknowledges funding from Michigan State University, the Sloan Foundation's Deep Carbon Observatory Grant G-2017-9954, and NSF EAR-1751664. J. Li acknowledges partial support from NSF AST 1344133, NASA NNX15AG54G, and Sloan Foundation Deep Carbon Observatory Grant G-2017-9954.

\section{Editor: Simon Redfern}

\section{Author Contributions}

J. Liu and S.M. Dorfman designed research; J.C. Liu, S.M. Dorfman, M. Lv, J. Li, F. Zhu, Y. Kono performed experiments; J. Liu analysed the data and built the model; J. Liu and S.M. Dorfman wrote the paper.

\section{Additional Information}

Supplementary Information accompanies this letter at http:// www.geochemicalperspectivesletters.org/article1919.

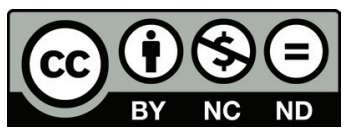

This work is distributed under the Creative Commons Attribution Non-Commercial No-Derivatives 4.0 License, which permits unrestricted distribution provided the original author and source are credited. The material may not be adapted (remixed, transformed or built upon) or used for commercial purposes without written permission from the author. Additional information is available at http://www.geochemicalperspectivesletters.org/ copyright-and-permissions.

Cite this letter as: Liu, J., Dorfman, S.M., Lv, M., Li, J., Zhu, F., Kono, Y. (2019) Loss of immiscible nitrogen from metallic melt explains Earth's missing nitrogen. Geochem. Persp. Let. $11,18-22$

\section{References}

Alexander, C.M.O., Howard, K.T., Bowden, R., Fogel, M.L. (2013) The classification of $\mathrm{CM}$ and $\mathrm{CR}$ chondrites using bulk $\mathrm{H}, \mathrm{C}$ and $\mathrm{N}$ abundances and isotopic compositions. Geochimica et Cosmochimica Acta $123,244-260$.

Badro, J., Brodholt, J.P., Piet, H., Siebert, J., Ryerson, F.J. (2015) Core formation and core composition from coupled geochemical and geophysical constraints. Proceedings of the National Academy of Sciences 112, 12310-12314

Bergin, E.A., Blake, G.A., Ciesla, F., Hirschmann, M.M., Li, J. (2015) Tracing the ingredients for a habitable earth from interstellar space through planet formation. Proceedings of the National Academy of Sciences $112,8965-8970$.
Brenker, F.E., Vollmer, C., Vincze, L., Vekemans, B., Szymanski, A., Janssens, K., SzAloki, I., NAsdala, L., Joswig, W., Kaminsky, F. (2007) Carbonates from the lower part of transition zone or even the lower mantle. Earth and Planetary Science Letters 260, 1-9.

Dalou, C., Hirschmann, M.M., VOn Der Handt, A., Mosenfelder, J., ARMSTRONG, L.S. (2017) Nitrogen and carbon fractionation during core-mantle differentiation at shallow depth. Earth and Planetary Science Letters 458, 141-151.

Fegley, B. (1983) Primordial retention of nitrogen by terrestrial planets and meteorites. Journal of Geophysical Research: Solid Earth 88, A853-A868.

FEI, Y., BROSH, E. (2014) Experimental study and thermodynamic calculations of phase relations in the $\mathrm{Fe}-\mathrm{C}$ system at high pressure. Earth and Planetary Science Letters 408, 155-162.

GRADY, M.M., WrIGHT, I.P. (2003) Elemental and Isotopic Abundances of Carbon and Nitrogen in Meteorites. Space Science Reviews 106, 231-248.

Grumbach, M.P., Martin, R.M. (1996) Phase diagram of carbon at high pressures and temperatures. Physical Review B 54, 15730-15741.

Guillermet, A.F., DU, H. (1994) Thermodynamic Analysis of the Fe-N System Using the Compound-Energy Model with Predictions of the Vibrational Entropy. Zeitschrift Fur Metallkunde 85, 154-163.

HALlidAy, A.N. (2013) The origins of volatiles in the terrestrial planets. Geochimica et Cosmochimica Acta 105, 146-171.

Hin, R.C., Coath, C.D., Carter, P.J., Nimmo, F., Lai, Y.-J., Pogge von StrandmanN, P.A.E., Willbold, M., Leinhardt, Z.M., Walter, M.J., ElliotT, T. (2017) Magnesium isotope evidence that accretional vapour loss shapes planetary compositions. Nature 549, 511-515.

Hirschmann, M.M. (2016) Constraints on the early delivery and fractionation of Earth's major volatiles from $\mathrm{C} / \mathrm{H}, \mathrm{C} / \mathrm{N}$, and $\mathrm{C} / \mathrm{S}$ ratios. American Mineralogist 101, 540-553.

JAvoY, M. (1997) The major volatile elements of the Earth: Their origin, behavior, and fate. Geophysical Research Letters 24, 177-180.

KAMINSKY, F., WiRTH, R. (2017) Nitrides and carbonitrides from the lowermost mantle and their importance in the search for Earth's "lost" nitrogen. American Mineralogist 102, 1667-1676.

Kono, Y., Park, C., Kenney-Benson, C., Shen, G., Wang, Y. (2014) Toward comprehensive studies of liquids at high pressures and high temperatures: Combined structure, elastic wave velocity, and viscosity measurements in the Paris-Edinburgh cell. Physics of the Earth and Planetary Interiors 228, 269-280.

Kono, Y., Kenney-Benson, C., Shibazaki, Y., Park, C., Wang, Y., Shen, G. (2015) X-ray imaging for studying behavior of liquids at high pressures and high temperatures using Paris-Edinburgh press. Review of Scientific Instruments 86, 072207.

KOWALSKI, M., SPENCER, P.J. (1995) Thermodynamic reevaluation of the C-O, Fe-O and Ni-O systems: Remodelling of the liquid, BCC and FCC phases. Calphad 19, 229-243.

LiU, J., Li, J., Hrubiak, R., Smith, J.S. (2016) Origins of ultralow velocity zones through slab-derived metallic melt. Proceedings of the National Academy of Sciences 113, 5547-5551.

LOCK, S.J., STEWART, S.T. (2017) The structure of terrestrial bodies: Impact heating, corotation limits, and synestias. Journal of Geophysical Research: Planets 122, 2016JE005239.

MARTY, B. (2012) The origins and concentrations of water, carbon, nitrogen and noble gases on Earth. Earth and Planetary Science Letters 313-314, $56-66$.

Mikhail, S., BARry, P.H., SverJensky, D.A. (2017) The relationship between mantle $\mathrm{pH}$ and the deep nitrogen cycle. Geochimica et Cosmochimica Acta 209, 149-160.

Norris, C.A., WooD, B.J. (2017) Earth's volatile contents established by melting and vaporization. Nature 549, 507-510.

RoHrbach, A., Schmidt, M.W. (2011) Redox freezing and melting in the Earth's deep mantle resulting from carbon-iron redox coupling. Nature $472,209-212$

Roskosz, M., Bouhifd, M.A., Jephcont, A.P., Marty, B., Mysen, B.O. (2013) Nitrogen solubility in molten metal and silicate at high pressure and temperature. Geochimica et Cosmochimica Acta 121, 15-28.

Rubie, D.C., Frost, D.J., Mann, U., Asahara, Y., Nimmo, F., Tsuno, K., Kegler, P., Holzheid, A., Palme, H. (2011) Heterogeneous accretion, composition and core-mantle differentiation of the Earth. Earth and Planetary Science Letters 301, 31-42.

SpeELmanNs, I.M., SCHMidT, M.W., LiebSKE, C. (2018) Nitrogen Solubility in Core Materials. Geophysical Research Letters 45, 7434-7443.

TsunO, K., OHTANI, E., TerasaKI, H. (2007) Immiscible two-liquid regions in the $\mathrm{Fe}-\mathrm{O}-\mathrm{S}$ system at high pressure: Implications for planetary cores. Physics of the Earth and Planetary Interiors 160, 75-85.

Yoshioka, T., Wiedenbeck, M., SHCheKA, S., Keppler, H. (2018) Nitrogen solubility in the deep mantle and the origin of Earth's primordial nitrogen budget. Earth and Planetary Science Letters 488, 134-143. 